Original Research Paper

\title{
A Unified Approach for the Shear Buckling Design of Structural Glass Walls with Non-Ideal Restraints
}

\author{
Chiara Bedon and Claudio Amadio \\ Department of Engineering and Architecture (DIA), University of Trieste, Trieste, Italy
}

\author{
Article history \\ Received: 01-01-2016 \\ Revised: 18-01-2016 \\ Accepted: 20-01-2016 \\ Corresponding Author: \\ Chiara Bedon \\ Department of Engineering and \\ Architecture (DIA), University of \\ Trieste, Trieste, Italy \\ Email: chiara.bedon@dia.units.it
}

\begin{abstract}
In this study, a unified design approach is assessed and proposed for the shear buckling verification of structural glass walls supported by non-ideal restraints. Based on the current trends of practice in buildings, the effect of (i) adhesive joints, (ii) metal frames with interposed adhesive joints or (iii) point mechanical connectors on the actual shear buckling behavior of the examined glass shear walls is properly investigated. The theoretical buckling resistance of the selected panels is first assessed by means of Finite-Element (FE) simulations, in the form of fundamental buckling shapes and Euler's critical loads. Analytical fitting curves of general applicability are proposed, so that the classical formulations derived from shear buckling theories could be used for a rational estimation of the Euler's critical loads, based on the restraints geometrical and mechanical features. As shown, the examined restraints have a fundamental role in the so predicted values and the assumption of ideal restraint configurations would unavoidably lead to unsafe, marked overestimations. Subsequently, the actual shear buckling resistance is also assessed, e.g., by taking into account the effects of possible initial geometrical imperfections, damage in glass or failure mechanisms in the restraints. Due to the implementation of accurate but computationally efficient FE models able to reproduce the desired mechanical effect of restraints, as well as any possible local damage in them, a rather close agreement is found with a standardized design buckling approach already in use for ideally simply supported glass shear walls only.
\end{abstract}

Keywords: Glass Shear Walls, Shear Buckling, Non-Ideal Restraints, Design Standardization, Finite-Element Numerical Modelling

\section{Introduction}

Only in recent years, the use in practice of glass panels and walls is a common trend in modern buildings, especially in façades. In most of the cases, these enclosures span from floor to floor (e.g., structural panels restrained at the level of the inter-story floors), in the form of full-height transparent elements able to primarily ensure lightness, transparency and energy efficiency to wide surfaces and interiors, as well as to ensure high aesthetic impact to buildings. Only in the recent years, however, the concept of 'structural glass walls' able to ensure a certain level of strength and stiffening contribution to entire buildings has been also developed, leading to the implementation in structural systems of glass panels able to carry on compressive, bending and shear forces due to the external loads (e.g., uniform pressures acting orthogonally to the plane of glass, in-plane compressive loads deriving from the adjacent structural background, or in-plane shear loads due to pressures acting along a direction parallel to the same glass panels' surface). As a result, their design and calculation strictly depends on a complex structural interaction between the glass panels themselves and their connections to the substructures, namely consisting in glued bonded connections, adhesive joints, special metal fasteners, steel or aluminum frames, as well as timber framing systems. In this sense, it is clear that an appropriate estimation of the effect of special restraints (compared to ideal boundary conditions) on the overall structural performance of these glass walls is mandatory. In doing so, based on the typical high slenderness ratios 
which characterize structural glass components in general, careful consideration should be paid especially for possible buckling phenomena.

\section{State-of-the-Art}

Over the past years, several researchers investigated the structural performance of shear glass walls and assemblies under in-plane quasi-static as well as dynamic loads, such in the case of seismic events. The major number of these past research projects has been dedicated to the development and validation of novel design concepts for the connection systems, as well as to the implementation and calibration of standardized design methods of practical use for glass shear walls under ordinary loads. Huveners et al. (2007) experimentally investigated the structural behavior of glass panels subjected to in-plane shear loads and circumferentially glued to metal frameworks. The structural interaction between glass panels and adhesively bonded steel frames has been also studied in (Richter et al., 2014). In (Memari et al., 2004; Behr, 2006), the dynamic behavior of full-scale curtain wall mock-ups was experimentally investigated were carried out to assess the seismic vulnerability and flexibility of glass façade panels under in-plane earthquake loads. Antolinc et al. (2014) also investigated, by means of full-scale shake-table experiments, the seismic capacity of glass walls interacting with timber frames.

Mocibob (2008) focused on the experimental and Finite-Element (FE) numerical investigation of the structural behavior of laminated glass panels under inplane shear loads, with specific attention for their shear buckling performance. In that study, careful consideration was paid for glass walls point supported to the substructure by means of bolted metal fasteners, as well as for glass panels linearly supported at the top and bottom edges only via partially rigid, flexible, linear adhesive joints. Wellershoff (2006) also accessed via experiments and FE simulations the buckling response of glass panels under in-plane shear and continuously, linearly supported along the four edges. Analytical and FE studies were proposed in (Bedon and Amadio, 2012) for the assessment of the buckling response and resistance of glass panels ideally simply supported along the four edges, under the action of in-plane shear loads. Based on a further validation of a simplified equivalent thickness approach, the study was then extended in (Amadio and Bedon, 2013) to laminated glass panels composed of two (or three) glass sheets and one (or two) shear flexible viscoelastic PVB films. In that case, the calibration of a Eurocode-based design curve to experimental test results of literature, FE simulations and analytical calculations was also proposed as a rational buckling design procedure for the examined loading and boundary conditions. The mentioned standardized design method, due to its general validity and simplicity of application, is currently implemented in technical document for structural glass elements (CNR-DT 210/2013). Its actual limitation, however, is represented by the assumption of ideal restraint conditions only (e.g., fully rigid, continuous simply supports along the four edges).

\section{Research Objectives}

In this study, the buckling response of glass panels subjected to in-plane shear loads is further investigated by means of extended $\mathrm{FE}$ parametric simulations (ABAQUS/Standard) and analytical methods. Careful consideration is paid, compared to earlier research contributions, to the overall effect of specific boundary conditions of practical use, e.g., (i) structural adhesive linear joints, (ii) metal frames with interposed adhesives, (iii) mechanical point fixings. Throughout FE parametric studies, the theoretical shear buckling response is first assessed, e.g., in terms of fundamental buckling shapes and Euler's critical load. As shown, as also in accordance with Mocibob (2008), the (i) to (iii) restraints typologies can strongly modify the shear behavior and ultimate resistance of the examined shear walls, compared to classical simply supports of clamp conditions. The overall shear buckling behavior, moreover, strictly depends on a combination of multiple aspects, e.g., the geometrical and mechanical properties of the glass panel alone as well as of the restraints (e.g., adhesive stiffness and thickness, out-of-plane bending stiffness of the metal frame, number and position of point mechanical connectors). As a result, an appropriate estimation and description of all the related global/local effects is mandatory for design purposes. In this study, buckling coefficients numerically derived from linear bifurcation FE simulations are proposed, together with appropriate analytical fitting curves of general applicability, so that for a given geometry and (i) to (iii) restraint typology, the corresponding Euler's critical load could be calculated based on classical formulations derived from shear buckling theories (Timoshenko and Gere, 1961). Based on extended nonlinear incremental FE analyses, the validity of the buckling design curve presented in (Amadio and Bedon, 2013) for ideally, continuously supported glass panels under in-plane shear, is also properly highlighted. As shown, due to the appropriate estimation of the effect of restraints on the corresponding shear buckling response, a rather good agreement is found, hence suggesting the extension of the same buckling design approach to various boundary conditions of practical interest. 
A practical case study is also proposed, in conclusion, to further emphasize the effect of restraints on the actual shear buckling response of a given glass panel.

\section{Theoretical Shear Buckling Background}

Often, buckling design methods proposed in literature for structural elements composed of various construction materials are strictly derived from classical analytical formulations for plates, beams, columns, under the hypotheses of ideal mechanical material behavior as well as boundary and loading conditions. In doing so, the estimation of the corresponding Euler's critical load represent a firstalthough not fully exhaustive-information related to the expected buckling performance for the structural element object of study.

When assessing the shear buckling response of a monolithic, fully isotropic panel subjected to in-plane shear loads, for example, with reference to Fig. 1a, analytical calculations are usually performed by taking into account classical formulations derived from literature (Timoshenko and Gere, 1961), that is by assuming that (i) the material has an elastic, homogeneous, isotropic behavior; (ii) the panel is initially perfectly flat and its thickness is small, compared to the global dimensions; (iii) the strains due to deflection in the middle surface are negligible, compared to strains due to bending; and (iv) deformations are such that straight lines initially normal to the middle surface remain straight and normal. The corresponding Euler's critical shear load is given by:

$V_{c r, 0}^{(E)}=\frac{\pi^{2} D}{b} k_{\tau}$

where, $D=E t^{3} / 12\left(1-v^{2}\right)$ denotes the bending stiffness of the panel of Fig. 1a, with $b$ and $H$ its global dimensions; $t$ is the nominal thickness; $E$ the Young's modulus and $v$ the Poisson' ratio. In the same Equation, $k_{\tau}$ is the buckling coefficient depending on the assigned boundary conditions and the aspect ratio $\alpha=H / b$. For panels with fully simply supported edges ('ss-ss'), $k_{\tau}$ is (Timoshenko and Gere, 1961):

$k_{\tau}= \begin{cases}4.00+\frac{5.34}{\alpha^{2}} & \alpha \leq 1 \\ 5.34+\frac{4.00}{\alpha^{2}} & \alpha>1\end{cases}$

As far as the actual restraints can be rationally assumed to behave as ideal, continuous simply supports or fully clamps, the Euler's critical load given by
Equation 1 can represent a useful and rational estimation of the expected buckling resistance of a given panel under in-plane shear loads $V$.

\section{Typical Restraints for Glass Shear Walls in Buildings: Case Studies}

When specific restraints are used in practice, appropriate studies should be carried out, e.g., in the form of detailed but often time consuming FE simulations, so that the effect of these restraints on the global structural response of the examined shear walls could be properly taken into account. In modern building applications, glass shear walls are in fact often supported by means of (i) linear adhesive joints (Fig. 2a), (ii) metal frameworks (Fig. 2b), (iii) mechanical point fixings (Fig. 3a). Especially (i) adhesive joints and (iii) point mechanical connectors are used because of their ability to minimize the need for bracing systems.

In the first case (i), Fig. 2a, the typical connection takes the form of a two-side adhesive joint applied along the top and bottom edges only of glass, with vertical edges fully unrestrained. Additional small steel supports, working as unilateral compressive restraints only, are used to transmit the compressive reaction forces from the glass panel to the structural background (Mocibob, 2008). Further small gaskets and spacers (see for example the cross-sectional detail of Fig. 2c) are used to kept fix the glass panel in the desired position, hence to allow possible rotations within the restraining system itself.

The same design concept was extended in (Amadio and Bedon, 2015), by introducing metal bracing components (e.g., mullions with a given out-ofplane bending stiffness) able to provide further restraint against possible deformations of the panel (Fig. 2b). In this latter case, the shear buckling response of the examined panels results from a combination of multiple geometrical and mechanical aspects, e.g., depending on the features of the glass panel only, the metal frame and the interposed adhesive joints.

The last examined restraint condition (iii), finally, is characterized by the presence of mechanical pointfixings only. The detail of Fig. $3 \mathrm{~b}$ represents the typical mechanical point-fixing for glass applications, namely consisting in a stainless steel head and a soft layer gasket (e.g., a polymeric ('POM') spacer) or a small mortar layer (Mocibob, 2008)) able to improve the distribution and propagation of maximum tensile stresses near the glass hole edges. Such point-fixing connectors typically provide transnational and rotational restraints to the supported glass panels, hence their actual working mechanism should be properly taken into account. 


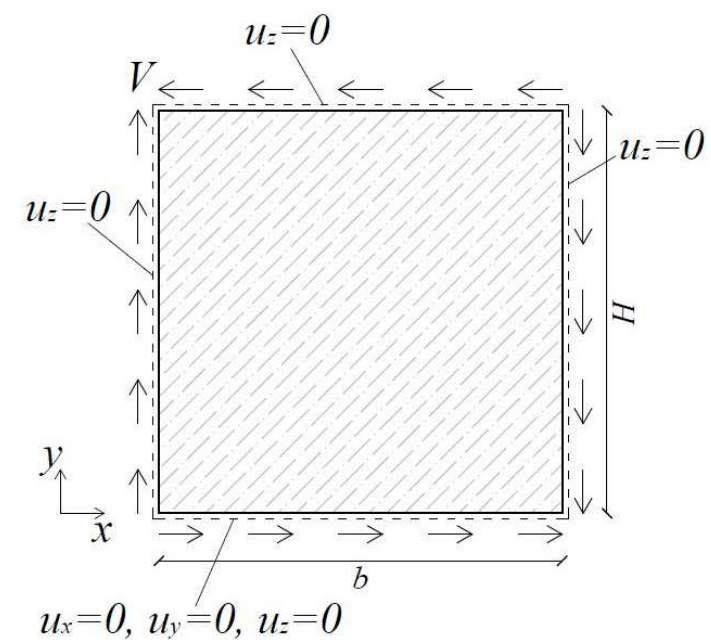

(a)

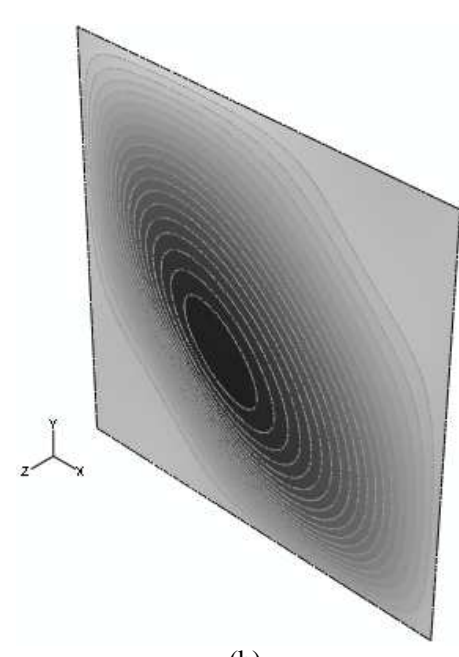

(b)

Fig. 1. Theoretical model for a simply supported, isotropic plate under in-plane shear. (a) Reference system and (b) fundamental deformed shape

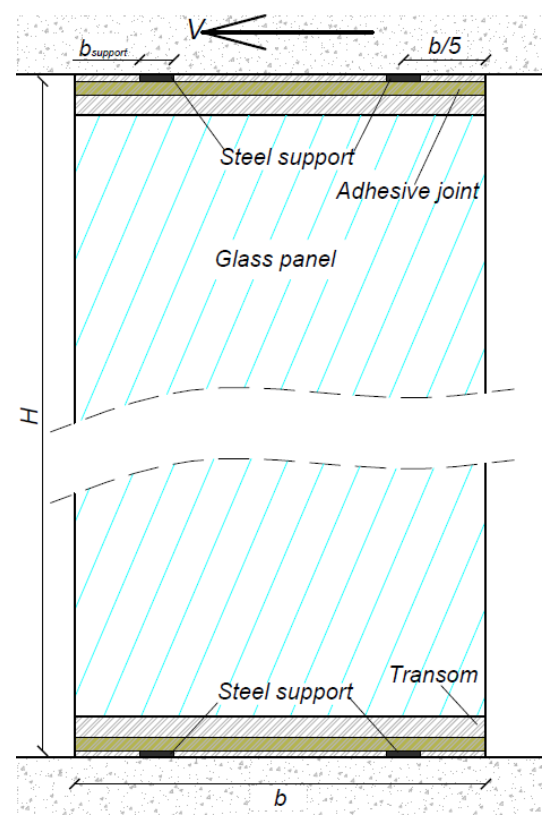

(a)

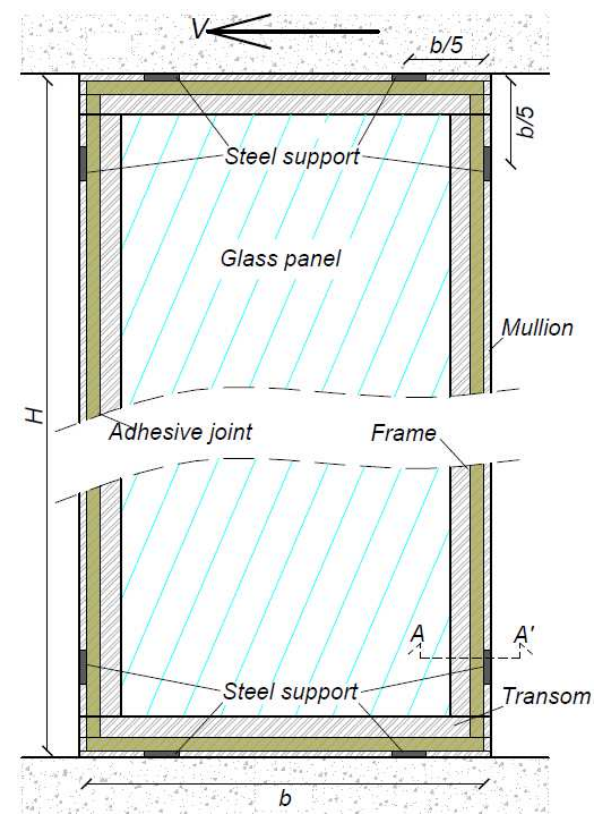

(b)

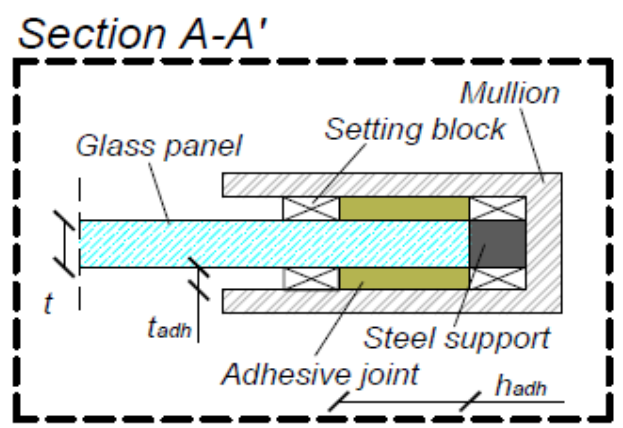

(c)

Fig. 2. Reference practical cases for the shear buckling assessment of glass walls. (a) Linear adhesive joints or (b) metal frame with interposed adhesive joints, with (c) cross-sectional detail 

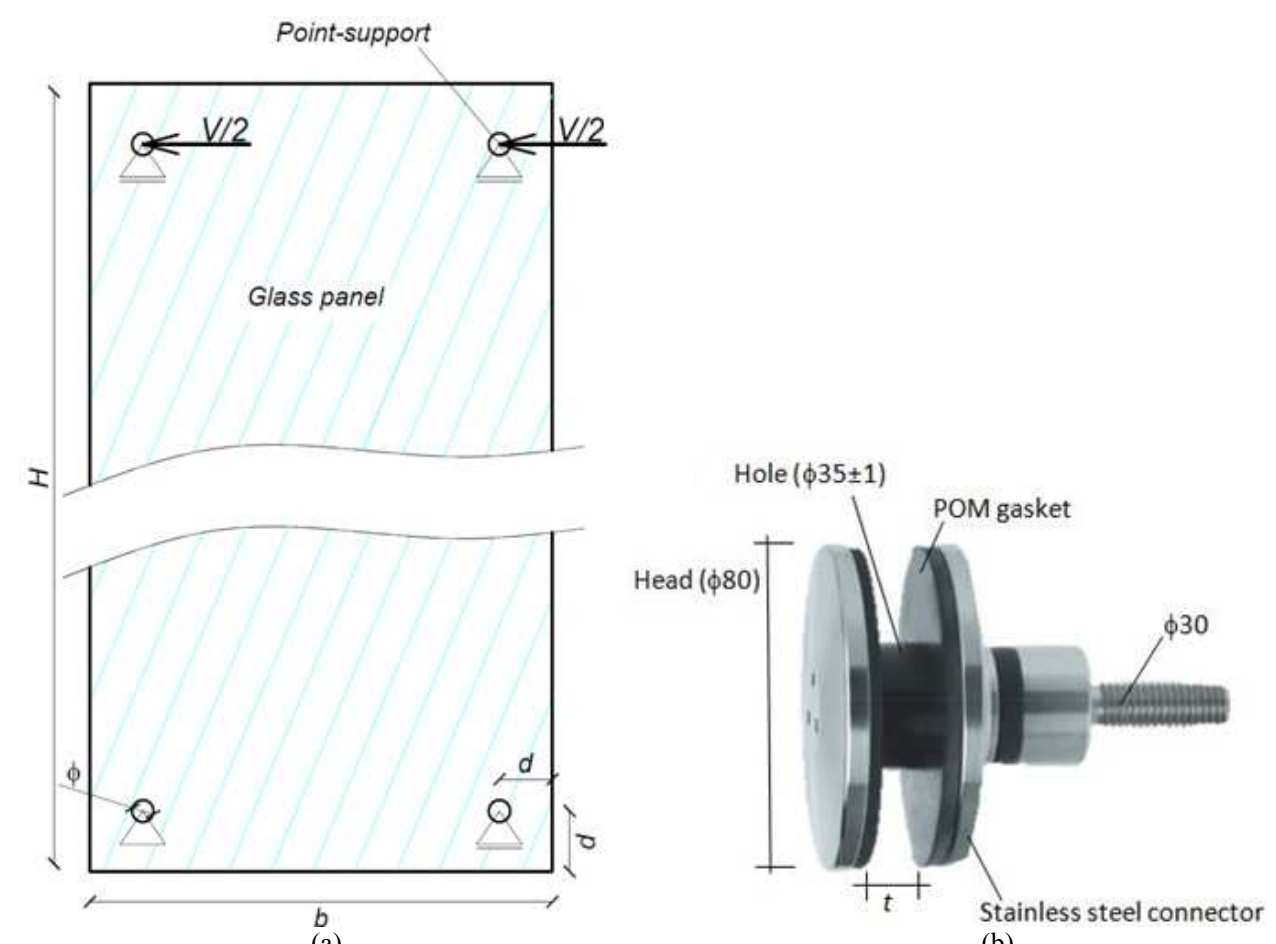

(a)

(b)

Fig. 3. Reference practical cases for the shear buckling assessment of glass walls. (a) Mechanical point-fixings and (b) example of connector detail

Through the current exploratory investigation, the number and position of these point connectors is originally set equal to $n_{b}=4$, with $\phi=42 \mathrm{~mm}$ the glass hole diameter and $d=100 \mathrm{~mm}$ the distance from each hole center to the panel edges (see also Mocibob, 2008), while subsequently the configurations with $n_{b}=6$ or 8 point connectors vertically aligned onto two columns, with $100 \leq d \leq 150 \mathrm{~mm}$, are also investigated.

\section{Exploratory Finite-Element Investigations}

\section{Geometrical and Mechanical Description of Glass Walls}

The typical FE-model was implemented in the ABAQUS/Standard computer software (Simulia, 2015) and consisted of 4-node shell elements composed of glass and characterized by a monolithic thickness $t$.

All the FE simulations were in fact carried out both on monolithic and three-layer laminated glass panels. In the latter case, the nominal sandwich cross-section composed of two glass sheets ( $t_{1}$ and $t_{2}$ the thicknesses) and a middle bonding foil ( $t_{i n t}$ the thickness and $G_{i n t}$ the shear modulus) was approximated in the form of a fully monolithic resisting section composed of glass, in which the equivalent thickness $t=t_{e q}=f\left(t_{1}, t_{2}, t_{i n t}, E\right.$, $G_{i n t}$ ) was calculated as proposed in (Amadio and Bedon, 2013) for three-layer laminated glass panels under in-plane shear. For all the specific load-time and temperature conditions taken into account through the FE parametric study, the corresponding shear modulus $G_{\text {int }}$ was carefully estimated, based on master curves available in literature for PVB or SG foils (see for example (Van Duser et al., 1999; Bennison et al., 1999)).

In the implementation of the aforementioned equivalent thickness approach, glass was mechanically described in the form of an indefinitely linear elastic material, with $E=70 \mathrm{GPa}, v=0.23$ the Young's modulus and Poisson' ratio respectively (EN 572-2, 2004). In this sense, any possible tensile or crushing failure mechanism in glass was manually checked during the analyses, by continuously monitoring the maximum tensile/compressive stresses in glass (see the Section 'General FE solving method').

\section{Geometrical and Mechanical Calibration of the Non-Ideal Restraints}

Careful consideration was given to the geometrical and mechanical description of the examined restraints, e.g., the linear adhesive joints (Fig. 2a), the metal frames with interposed adhesive joints (Fig. 2b) and the point mechanical connectors (Fig. 3a), being these restraints representative of the main influencing parameter for the purpose of the current FE numerical study. The computational accuracy and efficiency of the FE models were ensured by using equivalent axial springs with damage mechanical models, unilateral point connectors 
or surface-to-surface interactions, depending on the specific restraint typology. Figure 4 provides an overview of the main FE modelling assumptions.

In the case of adhesive joints (i), Fig. 4a, equivalent springs rigidly connected to ground were used to take into account the in-plane stiffness of the used adhesive layers. The presence of small gaskets able to avoid any possible rotation of the glass panel within the L-shaped metal devices (Fig. 2a) was taken into account in the form of rotational restraints only, for the interested mesh nodes.

The same modelling approach was partly implemented also for the panels with metal frames and interposed adhesive joints (ii), Fig. 4b. In this latter case, the equivalent axial springs representative of the adhesive layers were interposed between the glass panels' edges and the frame nodes, being this latter described in the form of beam elements. The small unilateral, steel supports working in compression only were then described in the form of mechanical connectors with fully rigid compressive stiffness but null resistance against possible tensile reaction forces.

In the case of glass panels with mechanical pointfixing connectors (iii), finally, careful consideration was paid for the mechanical calibration of the model in the vicinity of the point supports only, Fig. 4c. The single point connector was described in the form of full 3D brick elements composed of steel, while 4-node shell elements were used again for the implementation of the 'soft' layer interposed between the point connectors and the glass holes' edges. A surface-to-surface contact interaction was then introduced at the interface between the solid connector and the soft layer, so that compressive reaction forces could be only transmitted from the point connector to the glass panel (e.g., fully rigid, unilateral contact interaction with null tensile resistance/stiffness). For this purpose, the mesh pattern of glass was properly enhanced (see the detail of Fig. 4c).

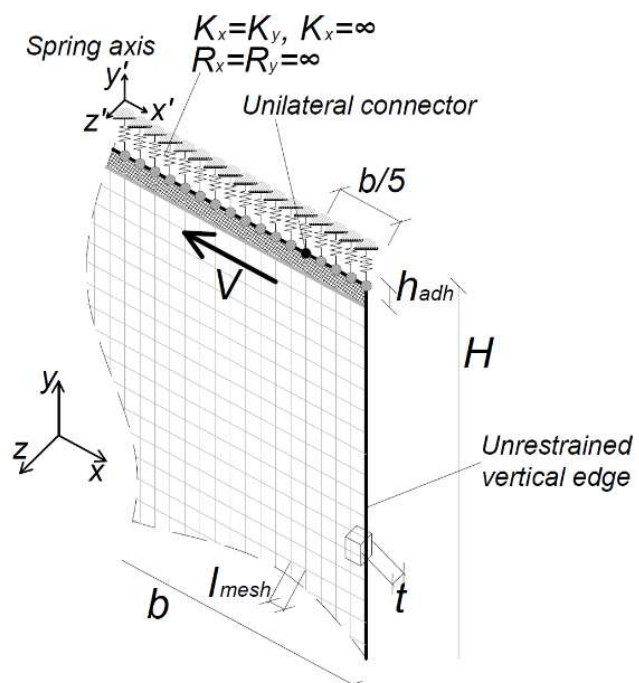

(a)

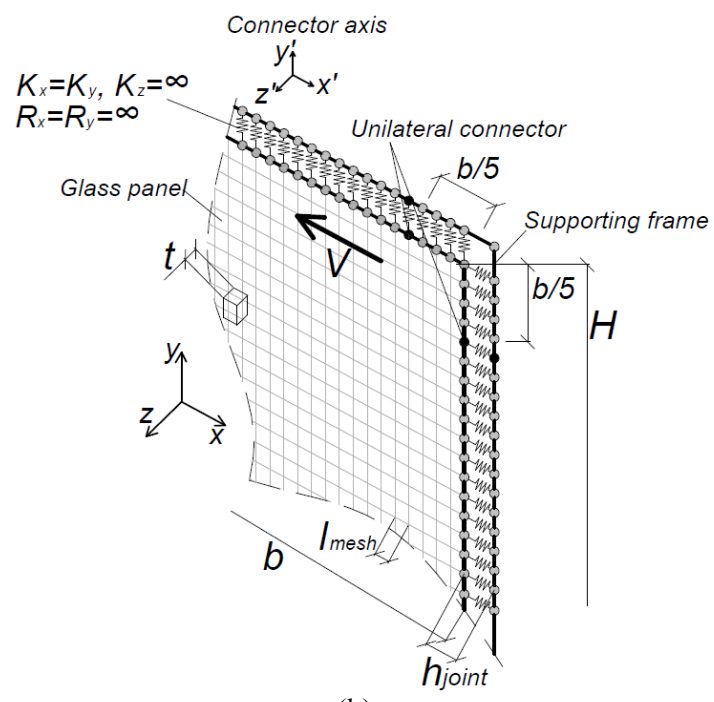

(b)

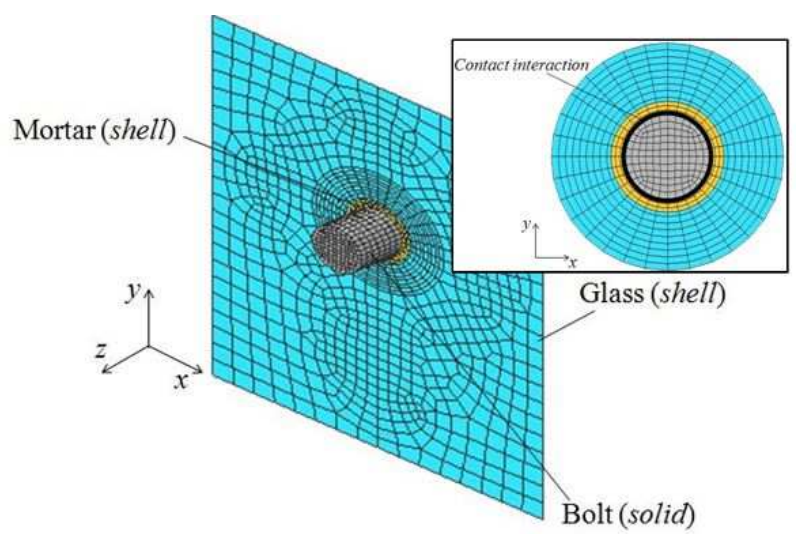

(c)

Fig. 4. Overview of the typical FE modelling approach for the implementation of the restraint details in glass shear walls. (a) Linear adhesive joints, (b) metal frame with interposed adhesive joints and (c) mechanical point-fixing connectors 
A detailed description of the full FE mechanical calibration of the (i) to (iii) restraint typologies can be found respectively in (Bedon and Amadio, 2016a; Amadio and Bedon, 2015; Bedon and Amadio, 2016b), together to a preliminary FE validation towards experimental results available in literature for small specimens/components.

\section{General FE Solving Method}

Both linear bifurcation analyses $(l b a)$ and geometrical incremental nonlinear simulations (inls) were carried out on the reference geometrical cases discussed above. The same FE mechanical modelling approach was used both for lba and inls analyses. In the first case ( $l b a$ simulations), qualitative assessment of the role of restraints was carried out in terms of fundamental buckling shapes and Euler's critical loads. In the latter case (inls study), the overall shear buckling response was investigated, with careful consideration for the shape and amplitude of possible initial geometrical imperfections (with $H / 1000$ the minimum recommended amplitude, in absence of more accurate data).

Due to the basic assumption of fully linear elastic constitutive law for glass, any possible damage mechanism (both tensile or crushing phenomena) were in fact detected as the first attainment on glass surface of maximum principal stresses exceeding the characteristic tensile and compressive resistances respectively, in accordance with the nominal values derived from product standards (EN 572-2, 2004).

In view of a validation of a past design buckling curve currently implemented in the Italian technical document CNR-DT 210/2013, the ultimate shear buckling resistance was generally detected as the first attainment of possible:

- $\quad$ Tensile cracking in glass

- $\quad$ Crushing mechanisms (e.g., in the vicinity of pointfixings and steel supports)

- $\quad$ Maximum out-of-plane deformations exceeding a pre-fixed value $(H / 300$, in this case, in accordance with (Amadio and Bedon, 2013))

\section{Derivation of Closed-Form Solutions for the $\boldsymbol{k}_{\tau}$ Buckling Coefficients}

A first exploratory investigation was carried out in the form of parametric linear bifurcation analyses $(l b a)$, for all the examined restraint typologies. Based on Equation $1, k_{\tau}$ was in fact reasonably derived as:

$$
k_{\tau}=\left(V_{c r, 0}^{(E)}\right)_{l b a} \frac{b}{\pi^{2} D}
$$

\section{Linear Adhesive Joints (i)}

Variations in the geometrical/mechanical properties of the glass panels (e.g., overall dimensions and cross-section) and the adhesive (e.g., Young's modulus $E_{a d h}$ and crosssectional dimensions $\left.t_{a d h} \times h_{a d h}\right)$ were taken into account. Some of the so obtained FE results are proposed in Fig. 5a, where numerically estimated $k_{\tau}$ coefficients (ABAQUS-lba) are proposed as a function of the panels aspect ratio $\alpha$, while the difference between the collected plots is given by the stiffness $K_{a d h}$ of the adhesive connection, where:

$$
K_{a d h}=n_{a d h} \cdot\left(\frac{E_{a d h}}{2 \cdot\left(1+v_{a d h}\right)} \frac{h_{a d h}}{t_{a d h}}\right)
$$

in [MPa], $n_{a d h}=2$ for adhesive layers applied on both the glass panel faces, $v_{a d h}=0.49$ for the Poisson's ratio, while hadh and tadh the cross-sectional dimensions respectively (see the details provided in Fig. 2).

In Fig. 5a, in particular, the FE data and analytical fitting plots are expressed as a function of a 'reference' joint stiffness $K_{a d h}=K_{r e f}$. This $K_{r e f}$ value was calculated, in accordance with (Mocibob, 2008), by means of Equation 4 with $n_{a d h}=2, E_{a d h}=2.4 \mathrm{MPa}$ and $t_{a d h}=9.5$ $\mathrm{mm} \times h_{\text {adh }}=40 \mathrm{~mm}$ the nominal dimensions of a single adhesive layer (Fig. 2c).

By assuming $\left(k_{\tau}\right)^{*}$ as the value of the $\left(k_{\tau}, \alpha\right)$ curves for $\alpha=1$, it can be seen from Fig. 5a that the collected plots have almost a regular trend (e.g., at least as far as $K_{a d h}$ do not exceeds $\approx 5$ times the reference value, in this FE parametric study), generally expressed by fitting curves in the form:

$k_{\tau}=\frac{\left(k_{\tau}\right)^{*}}{\alpha^{y}} \approx \frac{\left(k_{\tau}\right)^{*}}{\alpha^{3}}$

which well agrees with findings results proposed in (Mocibob, 2008) and:

$$
\left(k_{\tau}\right)^{*}=\frac{K_{a d h}}{c_{1}}+c_{2}
$$

with $K_{a d h}$ given by Equation $4, c_{1}=12.2 \mathrm{MPa}$ and $c_{2}=$ 4.6.

For all the tested panel, as also in accordance with (Mocibob, 2008), the corresponding fundamental buckling shape was characterized by large out-ofplane deflections for the fully unrestrained vertical edges of glass, e.g., Fig. 7a.

\section{Metal Frames with Interposed Adhesive Joints (ii)}

As far as supporting mullions were added with increasingly out-of-bending stiffness to provide a certain bracing effect to the vertical edges of the examined glass panels (Fig. 2b), a shear buckling response rather sensitive to a multitude of combined aspects was observed (e.g., geometrical/mechanical properties of the glass panel only, the supporting metal frame, the interposed adhesive joints). 


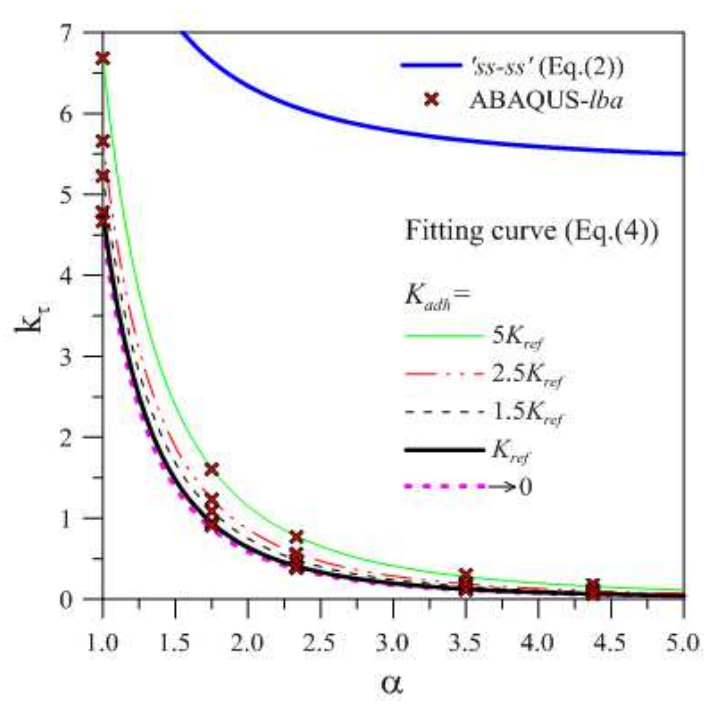

(a)

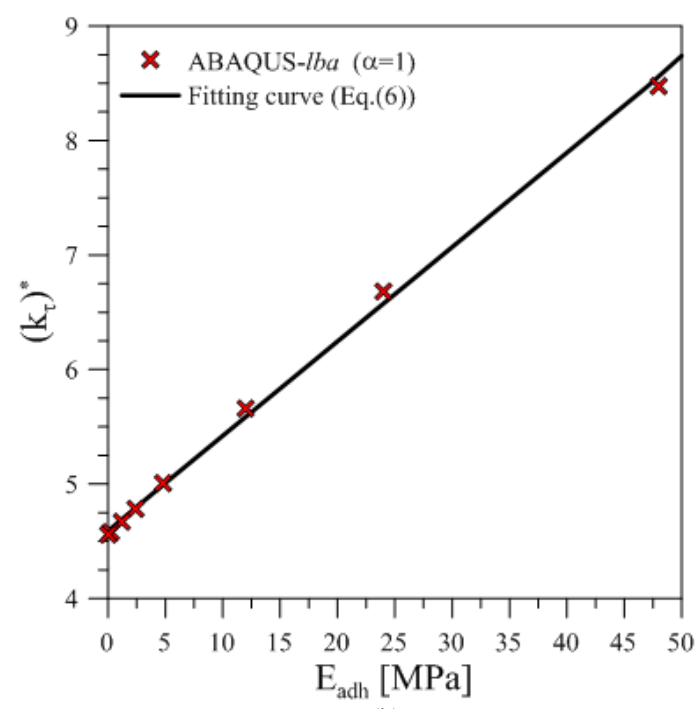

(b)

Fig. 5. FE numerically derived and analytical fitting curves for the $k_{\tau}$ buckling coefficient of linear adhesively restrained glass shear walls
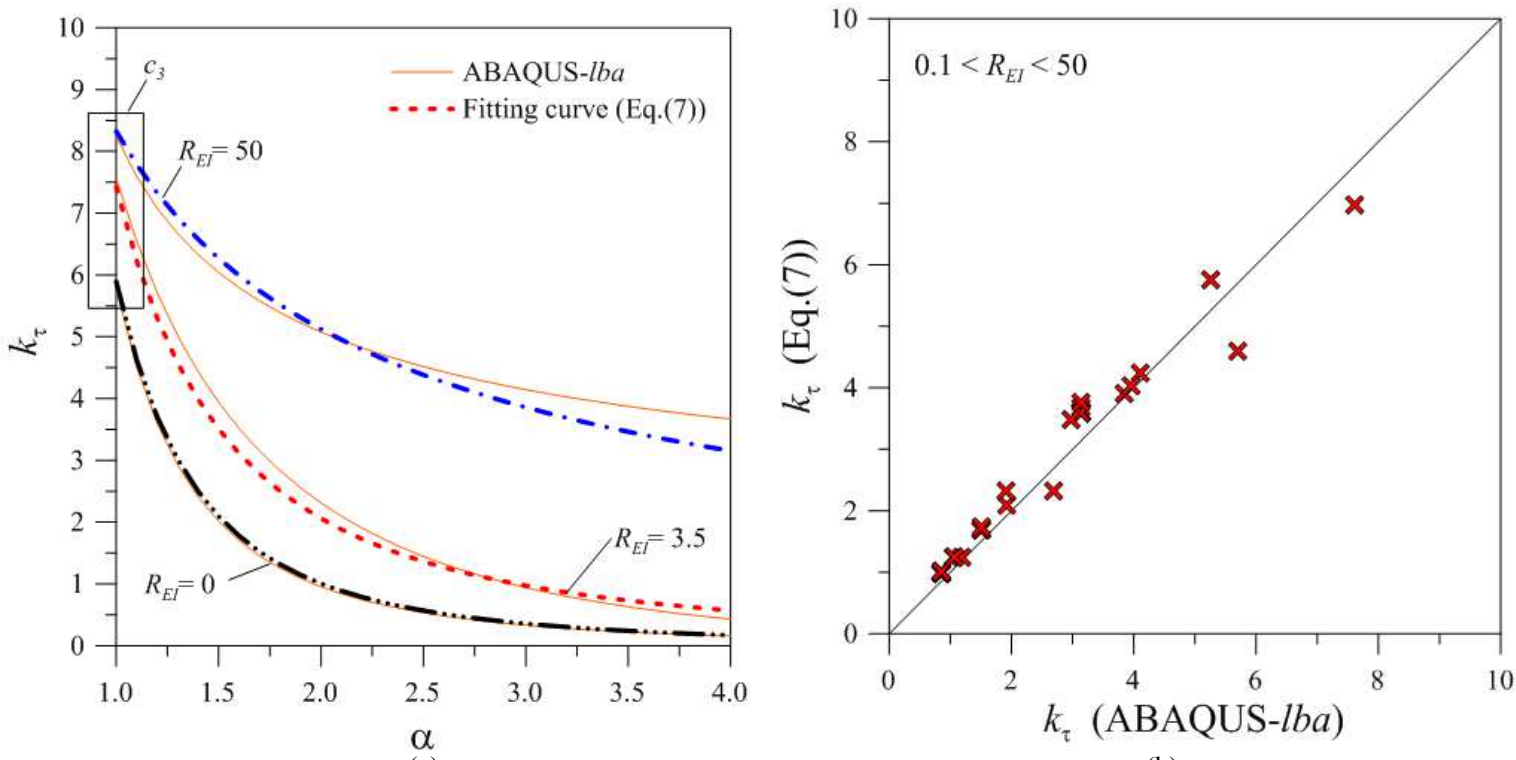

(a)

(b)

Fig. 6. FE numerically derived and analytical fitting curves for frame supported glass shear walls. (a) $\mathrm{k}_{\tau}$ buckling coefficients and (b) FE-analytical comparisons

In any case, all the collected lba FE data highlighted a general agreement with an analytical fitting curve defined in the form (Fig. 6a):

$$
k_{\tau}=\frac{c_{3}}{\alpha^{c_{4}}}
$$

with:

$$
c_{3}=X+0.39 \cdot \ln \left(R_{E I}\right)
$$

$$
c_{4}=\frac{1}{0.04 \cdot R_{E I}+0.365}
$$

and:

$$
R_{E I}=\frac{2 E I_{m}}{E I_{g}}
$$

a bending stiffness ratio, where $E I_{m}$ is the out-of-plane bending stiffness of a single supporting metal mullion and: 


$$
E I_{g}=E_{g} \cdot \frac{b t^{3}}{12}
$$

the bending stiffness of the glass panel only, while:

$$
X=c_{5} \cdot K_{a d h}+6.67
$$

And $c_{5}=0.03 \mathrm{MPa}^{-1}$ define the $c_{3}$ constant of Equation 8. Figure $6 \mathrm{~b}$ shows a parametric comparison between the FE predicted and analytically fitted $k_{\tau}$ buckling coefficients.

In terms of qualitative effect due to bracing mullions characterized by variable out-of-plane bending stiffness, a transition between the limit conditions of (i) glass panels with fully unrestrained vertical edges (Fig. 7a) and (ii) glass panels with almost fully rigidly restrained vertical edges (Fig. 7b) was also noticed. The typical fundamental buckling shapes, consequently, resulted comprised between the limit configurations (for the range of geometrical/mechanical properties of major interest in structural glass applications).

\section{Mechanical Point-Fixings (iii)}

In the case of point-supported glass panels under inplane shear, the $l b a$ study was performed by taking into account several geometrical configurations, e.g., overall dimensions and cross-sectional properties of the tested glass panels, as well as various configurations of point-

(a)

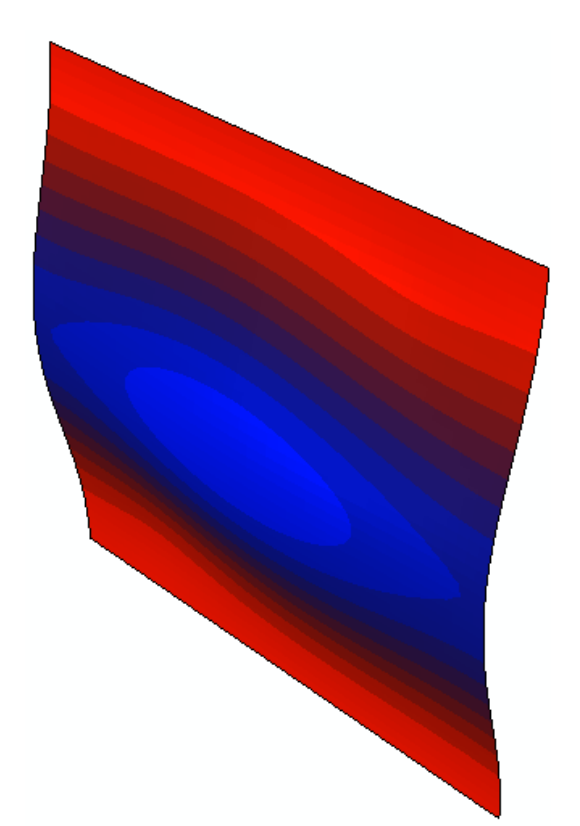

fixing restraints (e.g., $d=100,120,150 \mathrm{~mm}$ the distance of the holes center from the edges, or $n_{b}=4,6$ and 8 the total number of connectors).

In general, the performed $l b a$ studies highlighted a rather negligible sensitivity of the theoretical buckling resistance/buckling coefficients $k_{\tau}$ to the position of the point-connectors (e.g., the distance $d$ ) and an almost close agreement (for the $n_{b}=4,6,8$ examined configurations) with the following analytical fitting curve:

$k_{\tau}=\frac{c_{6}}{\alpha^{c_{7}}}$

being:

$c_{6}=1.88 \cdot n_{b}-3.46$

and $c_{7}=2$.

In the case of rectangular panels with $\alpha \geq \approx 1.5$ (e.g., being $n_{b}=4$ the conventional number of restraints in use for almost square panels), an almost linear correlation was in fact found between the total number $n_{b}$ of point restraints and the corresponding Euler's critical load $/ k_{\tau}$ coefficient (Fig. $8 \mathrm{a}$ and b). In this sense, compared to the $n_{b}=4$ reference case, the additional point supports $\left(n_{b}=6\right.$ or 8$)$ worked as intermediate rigid restraints able to progressively reduce the effective buckling length of the panel, Fig. $8 \mathrm{~b}$ and 9.

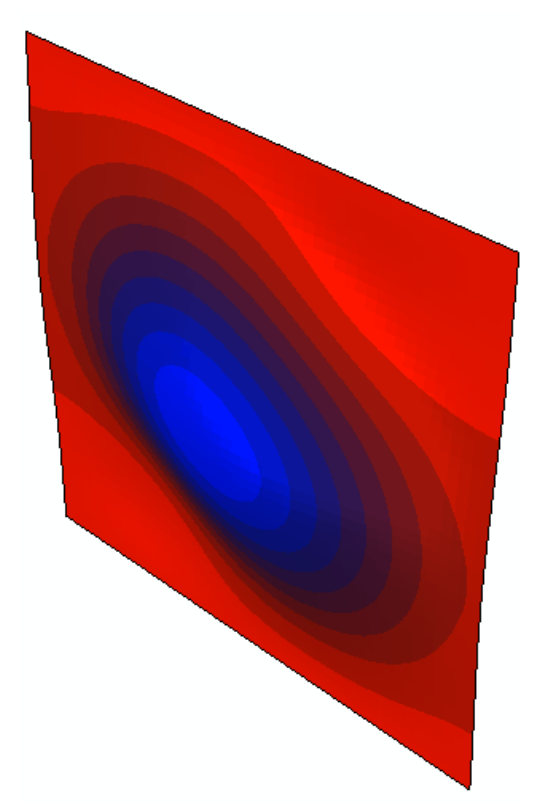

(b)

Fig. 7. FE fundamental buckling shapes for glass shear walls supported by metal frames with variable out-of-plane bending stiffness (ABAQUS/Standard). Red-to-blue contour plot, with maximum normalized displacements tending to red. (a) $R_{E I} \approx 0$ and (b) $R_{E I} \rightarrow \infty$ 


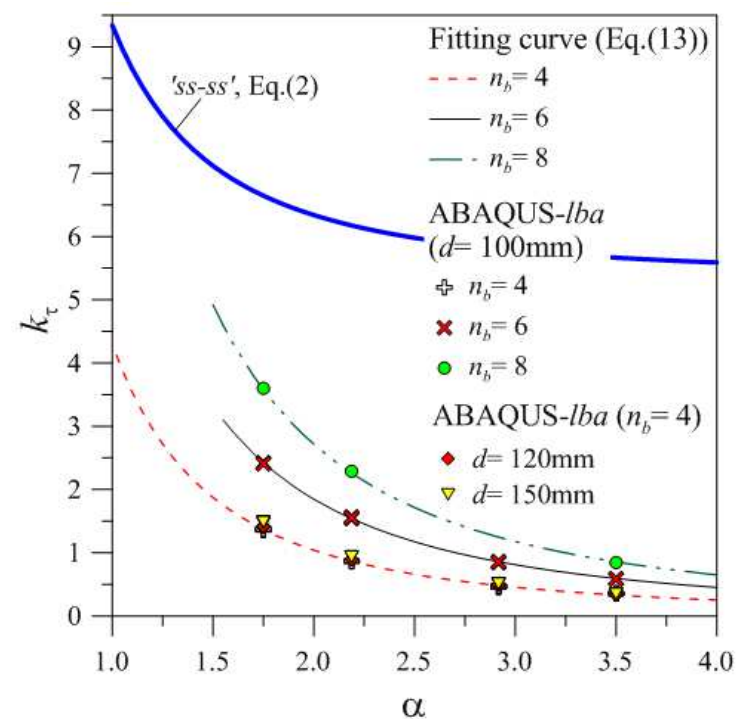

(a)

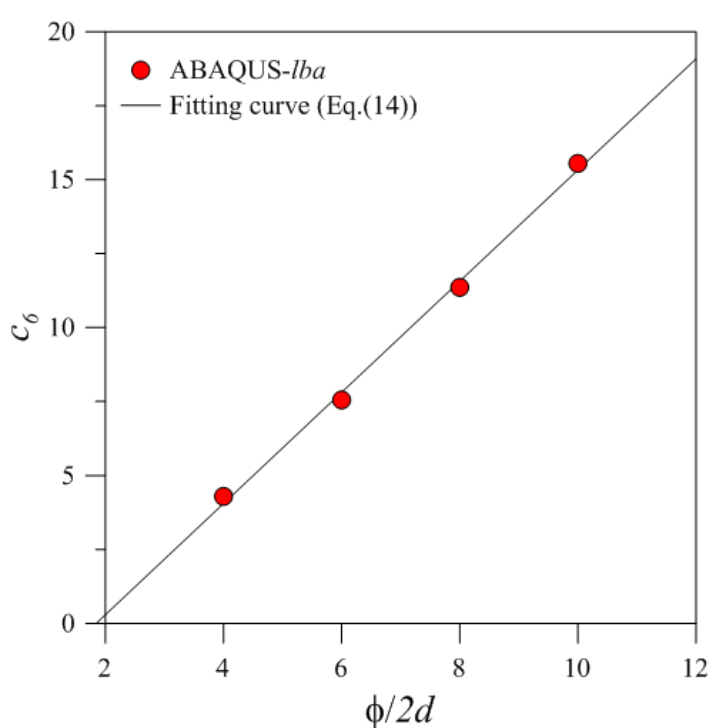

(b)

Fig. 8. FE numerically derived (ABAQUS/Standard) and analytical fitting curves for point supported glass shear walls. (a) $k_{\tau}$ buckling coefficients and (b) $c_{6}$ fitting curve
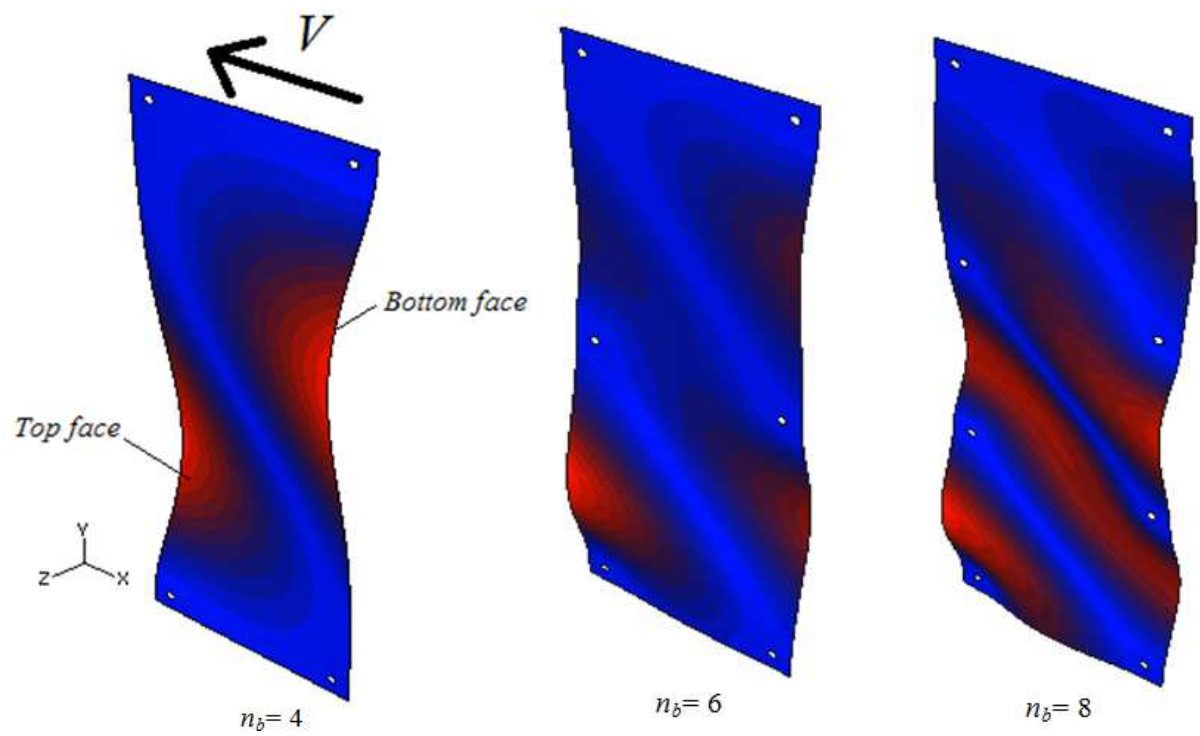

Fig. 9. Fundamental buckling shapes for glass shear walls with mechanical point connectors (ABAQUS/Standard)

\section{Towards a Unified Buckling Design Method}

As a conclusive step of this exploratory investigation, further inls parametric studies were carried out on a multitude of shear glass panels with various geometrical properties and restraint typologies. As far as the $l b a$ simulations provide an almost qualitative assessment of the expected shear buckling response for the examined panels, the same $l b a$ analyses are not able to take into account the effects of several important aspects like geometrical defects, mechanical damage phenomena, etc. and more detailed, geometrical nonlinear analyses (inls) are mandatory.

\section{Existing Standardized Formulation for Ideally Restrained Glass Shear Walls}

In this research contribution, the inls parametric simulations were carried out to assess and validate the accuracy of the standardized design method proposed in (Amadio and Bedon, 2013) for ideally simply supported glass plates under in-plane shear. In that 
case, a Eurocode-based design curve was in fact calibrated, so that the shear buckling verification of a given shear glass panel could be carried out as:

$$
V=V_{E d} \leq V_{b, R d}=\chi \frac{\tau_{R k} \cdot A^{*}}{\gamma_{M}}
$$

with $\tau_{R k}=\sigma_{R k}$ the nominal tensile resistance of glass (EN 572-2, 2004), $A^{*}=b t^{*}$ the resisting cross-sectional surface of glass only (to be calculated on the base of the total glass thickness $t^{*}$, both in the case of monolithic and laminated sections), $\gamma_{M}=1.4$ a material partial safety factor (Wellershoff, 2006) and:

$$
\chi=\frac{1}{\Phi+\sqrt{\Phi^{2}-\bar{\lambda}^{2}}} \text { for } \chi \leq 1
$$

A buckling reduction coefficient, where:

$$
\Phi=0.5\left[1+\alpha_{\text {imp }}\left(\bar{\lambda}-\alpha_{0}\right)+\bar{\lambda}^{2}\right]
$$

And:

$$
\bar{\lambda}=\sqrt{\frac{\tau_{R k} \cdot A^{*}}{V_{c r, 0}^{(E)}}}
$$

Is the normalized slenderness ratio, while $\alpha_{i m p}=$ 0.49, $\alpha_{0}=0.50$ represent the imperfection factors calibrated by taking into account an initial geometrical imperfection with $H / 1000$ the maximum amplitude (Amadio and Bedon, 2013).

\section{Non-ideally Restrained Glass Shear Walls}

The parametric FE data collected from the current inls study are proposed in Fig. 10, in non-dimensional form. There, the FE dots are proposed for adhesive/frame supported glass shear walls (Fig. 10a) and point supported panels (Fig. 10b) subjected to initial geometrical imperfections. For each configuration, the corresponding geometrical imperfection was derived from preliminary $l b a$ analyses and scaled up to $H / 1000$ the panel height.

The main difference between Fig. 10a and $b$ is represented by the normalization process for all the collected FE data. While in the first case the crosssectional resisting surface $A^{*}$ is still represented by the total $b t^{*}$ glass section, hence:

$$
\bar{\lambda}=\bar{\lambda}_{1}=\sqrt{\frac{\tau_{R k} \cdot A^{*}}{\left(V_{c r, 0}^{(E)}\right)_{l b a}}}
$$

And:

$$
\chi=\chi_{1}=\frac{V_{b, R d} \cdot \gamma_{M}}{\tau_{R k} \cdot A^{*}}
$$

For the point-supported shear walls the normalization approach was carried out by taking into account the effects due to glass holes, e.g., by calculating the corresponding slenderness ratio as:

$$
\bar{\lambda}=\bar{\lambda}_{2}=\sqrt{\frac{\tau_{R k} \cdot A_{n}^{*} / K_{t}}{\left(V_{c r, 0}^{(E)}\right)_{l b a}}}
$$

With:

$$
A_{n}^{*}=(2 d-\varphi) \cdot t^{*}
$$

The reduced resisting area and:

$$
K_{t}=3-3.13 \cdot\left(\frac{\varphi}{2 d}\right)+3.66 \cdot\left(\frac{\varphi}{2 d}\right)^{2}-1.53 \cdot\left(\frac{\varphi}{2 d}\right)^{3}
$$

The stress concentration factor (Peterson, 1953), while the buckling reduction factor was estimated as:

$$
\chi=\chi_{2}=\frac{V_{b, R d} \cdot \gamma_{M}}{\left(\frac{\tau_{R k} \cdot A_{n}^{*}}{K_{t}}\right)}
$$

The so normalized FE data, for both Fig. 10a and $\mathrm{b}$, are proposed by taking into account several glass types (e.g., annealed, heat strengthened and fully tempered) and their corresponding characteristic tensile resistance values (EN 572-2, 2004). In terms of compressive resistance, conversely, a conventional characteristic limit of $450 \mathrm{MPa}$ was considered $(\approx 10$ times the nominal tensile strength of float glass).

As shown, for all the examined mechanical and geometrical configurations, a rather close agreement was found between the FE data and the past standardized design approach (Equation 16). In the case of point supported glass panels only (Fig. 10b), modified imperfection factors $\alpha_{0}=0.30$ and $\alpha_{i m p}=1.40$ were also calibrated and proposed for safe estimations (e.g., due to the high sensitivity of this latter configuration to local failure phenomena, as especially emphasized by glass shear walls with $n_{b}=4$ ).

In the same Fig 10a and b, full-scale experimental results are proposed in normalized form, based on the 
few data available in literature for the examined design concepts (Mocibob, 2008). In the first case (Fig. 10a), a specimen consisting of a $1200 \mathrm{~mm}$ wide $\times 3500 \mathrm{~mm}$ high panel composed of two $8 \mathrm{~mm}$ thick heat strengthened glass plies and a middle $1.52 \mathrm{~mm}$ thick PVB interlayer was restrained by means of linear adhesive joints at the top/bottom edges only (Fig. 2a). The experimental test result was normalized by means of Equation 19 and 20, by taking into account the geometrical/mechanical properties of the specimen and the experimental buckling failure load (see also Mocibob, 2008). In the latter case (Fig. 10b), a point-supported specimen with the same geometrical and mechanical features of the first one was restrained by means of bolted connectors only (with $\phi=$ $42 \mathrm{~mm}$ and $d=100 \mathrm{~mm}$ respectively, Fig. 3a). The experimental test result was normalized, in this case, by means of Equation 21 and 24. For both the experiments, the corresponding 'analytical' calculation is also proposed ('white dot' of Fig. 10a and b), based on Equation 16 and 18. As shown, an interesting correlation was found between the proposed numerical/analytical methods and the full-scale test specimens, hence further suggesting the accuracy and validity of the implemented unified approach.

Certainly, additional extended investigations and fullscale experimental validations are required. In any case, the current research outcomes suggest the possible generalization of standardized buckling design methods

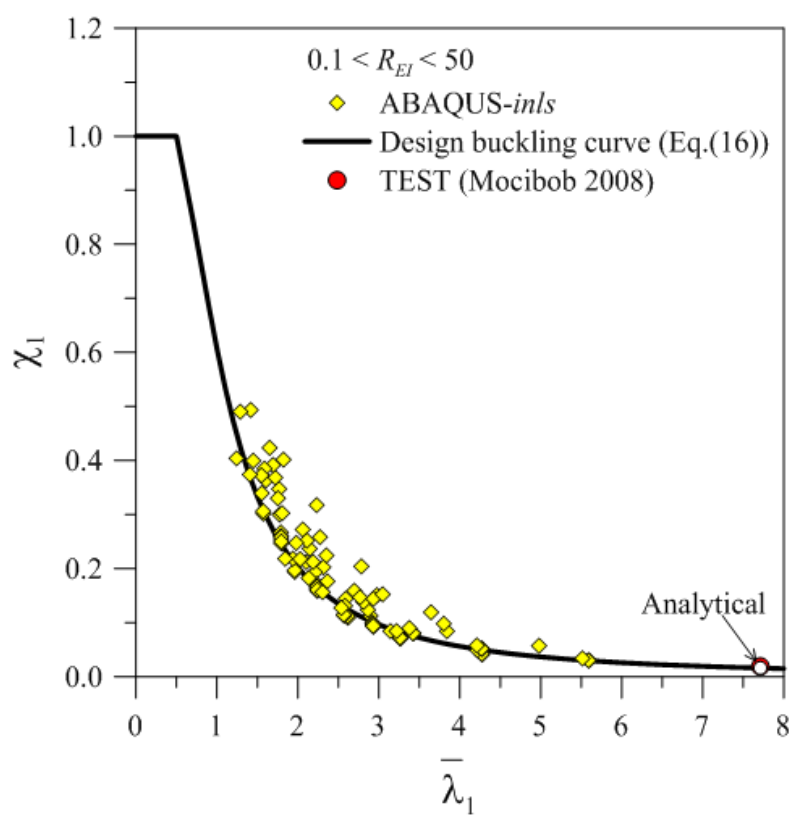

(a) to structural glass panels with variable restraint conditions.

\section{Practical Calculation Example}

As a practical example, a glass panel with overall dimensions $b=1000 \mathrm{~mm}$ and $H=3000 \mathrm{~mm}$ was finally taken into account. Its cross-section was supposed composed of two heat strengthened glass panels, with $t_{1}=t_{2}=12 \mathrm{~mm}$ the nominal thicknesses, bonded together by means of a PVB film (with $t_{i n t}=$ $1.52 \mathrm{~mm}$ the thickness). The shear buckling resistance of the so assembled panel was assessed towards the action of a short-term wind pressure with resultant force $V_{E d}$ acting in the plane of the glass wall itself. For the examined loading condition, a conventional duration of 30 seconds and a reference temperature of $20^{\circ} \mathrm{C}$ can be taken into account for design purposes (e.g., (CNR-DT 210/2013)), hence $G_{i n t}=8.06 \mathrm{MPa}$ was considered as the corresponding equivalent shear modulus for PVB.

Based on (Amadio and Bedon, 2013), a fully monolithic, equivalent thickness $t_{e q}=17.42 \mathrm{~mm}$ was used for the parametric analytical calculations, with $t^{*}=$ $24 \mathrm{~mm}$ the total thickness of glass only.

For the same geometrical configuration and loading condition, the shear buckling response was in fact investigated by taking into account several boundary configurations, geometrically and mechanically characterized as specified in Table 1.

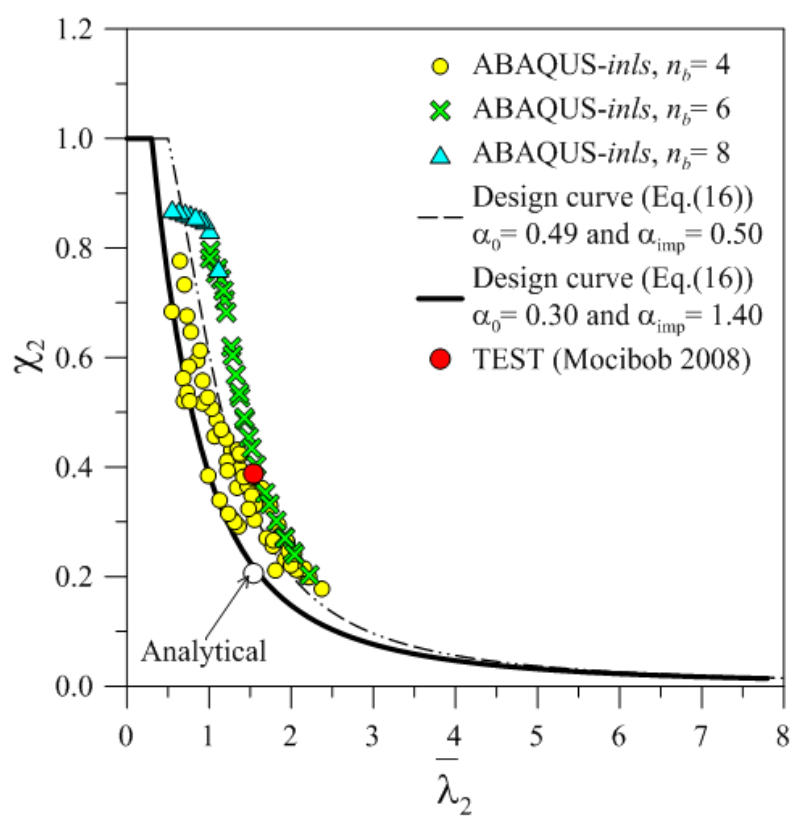

(b)

Fig. 10. Assessment of a past normalized design buckling curve (Equation 16) for glass shear walls with (a) adhesive joints and metal frame with interposed adhesive joints or (b) mechanical point-supports $\left(\gamma_{M}=1\right.$, for the normalization of ABAQUS-inls and experimental data) 
The main shear buckling parameters (e.g., critical load $V_{b, R d}$ and normalized slenderness ratio $\bar{\lambda}$ ) were calculated for the \#0 to \#10 configurations, based on Equation 15 and 18 respectively (with $A^{*}=A_{n}{ }^{*} / K_{t}$, in the case of point supported panels) and compared in nondimensional form in Fig. 11, where:

$$
R=\frac{p_{(\# 0)}}{p_{(\# i)}} i=0, \ldots 10
$$

denotes the ratio between the ' $p$ ' parameter for the \#0 restraint configuration (Table 1 ) and the other $\# i$-cases. For the 'ss-ss' (\#0) panel, specifically, the values $V_{b, R d}=$ $781.33 \mathrm{kN}$ and $\bar{\lambda}=0.95$ were obtained.

As shown in Fig. 11, as expected, a marked effect of restraints was found for all the examined restraint configurations. In terms of buckling resistance $V_{b, R d}$
(Fig. 11a), in particular, it can be noticed that the assumption of a conventional ' $s S$ - $s S$ ' reference case would lead to a marked overestimation of the actual design strength values, both for adhesively restrained $(\# 1, \# 2, \# 3)$, frame supported $(\# 4, \# 5, \# 6)$ and point supported panels $(\# 8, \# 9, \# 10)$. In most of the cases, the design resistance $V_{b, R d}$ was in fact found to be in the order of $\approx 0.1-0.3$ times the $\# 0$ value.

In the same Fig. $11 \mathrm{a}$, it is also interesting to notice that neither the presence of an almost fully rigid frame (\#7) would provide the same design strength of an idealized, continuous simply support along the four edges. This effect can be justified both by the presence of intermediate, flexible adhesive joints and by the occurrence of local failure mechanisms in glass (e.g., in the vicinity of the small unilateral steel supports, Fig. 2b).

Table 1. Reference restraint properties for the practical examples collected in Fig. 11

\begin{tabular}{|c|c|c|}
\hline Ref\# & Restraint typology & Main features \\
\hline 0 & $s S-S S$ & Idealized, continuous simply supports along the four edges (Fig. 1) \\
\hline 1 & Adhesive (i) & $\begin{array}{l}\text { Adhesive joints along the top/bottom edges only (Fig. } 2 \mathrm{a} \text { ), with } t_{\text {adh }}=9.5 \mathrm{~mm}, h_{\text {adh }}=40 \mathrm{~mm} \text {, } \\
n_{\text {adh }}=2 \text { and } E_{\text {adh }}=1.2 \mathrm{MPa} \text {, while } b / 5 \text { is the distance of small steel supports from the corners }\end{array}$ \\
\hline 2 & Adhesive (i) & The same of $\# 1$, but $E_{a d h}=2.4 \mathrm{MPa}$ \\
\hline 3 & Adhesive (i) & The same of $\# 1$, but $h_{\text {adh }}=80 \mathrm{~mm}$ \\
\hline 4 & Frame + adhesive (ii) & Metal frame + adhesive joints (Fig. $2 \mathrm{~b}$ ), with $R_{E I}=0.5$ and adhesive joints characterized as in $\# 1$ \\
\hline 5 & Frame + adhesive (ii) & The same of $\# 4$, but $R_{E I}=2$ \\
\hline 6 & Frame + adhesive (ii) & The same of $\# 4$, but $R_{E I}=10$ \\
\hline 7 & Frame + adhesive (ii) & The same of $\# 4$, but $R_{E I}=50$ (fully rigid frame) \\
\hline 8 & Point-fixing (iii) & Mechanical point-fixing connectors (Fig. 3a) with $d=100 \mathrm{~mm}, \phi=42 \mathrm{~mm}, n_{b}=4$ \\
\hline 9 & Point-fixing (iii) & The same of $\# 8$, but $n_{b}=6$ \\
\hline 10 & Point-fixing (iii) & The same of $\# 8 ;$ but $n_{b}=8$ \\
\hline
\end{tabular}

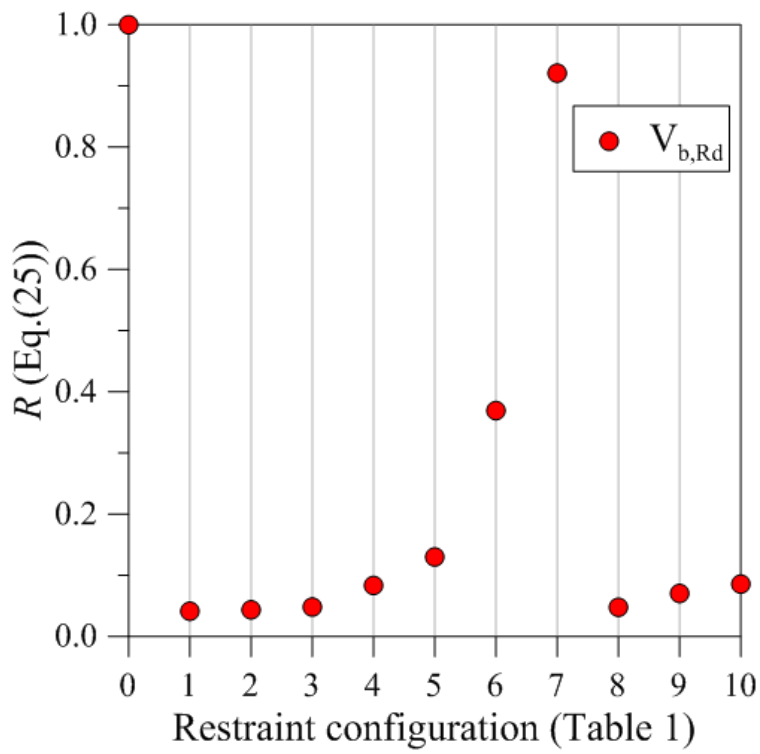

(a)

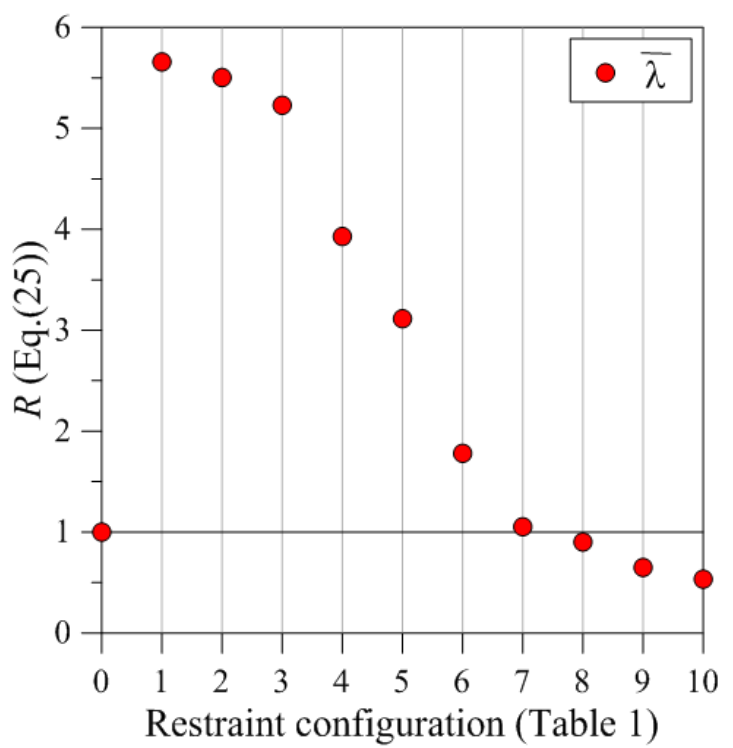

(b)

Fig. 11. Analytical comparative shear buckling calculations for a given glass wall geometry with several restraint typologies and subjected to a short term in-plane shear load. (a) Design critical buckling load (Equation 15) and (b) normalized slenderness ratio (Equation 18) 
In general, for the \#1 to \#10scenarios, the observed behaviors typically derived from a combination of aspects strictly related to both the mechanical and geometrical features of the adopted restraints and specifically on their influence in terms of global shear buckling response and actual normalized slenderness ratio (Fig. 11b), as well as in terms of development of specific, local failure mechanisms leading the glass panels to collapse. Careful consideration, consequently, should be paid in their design and verification under simple loading configurations as well as combined actions. In this sense, it is expected that the current research study could represent a valid theoretical background for the implementation and development of standardized design methods for glass structures, as well as for the further extension of the same design methods to complex loading scenarios.

\section{Conclusion}

In this study, the shear buckling response and actual resistance of structural glass walls with non-ideal restraints has been critically assessed by means of extended Finite-Element (FE) numerical investigations and analytical methods derived from classical theory. Careful consideration has been paid, in particular, to the effect that actual restraints of practical use in buildings can have in terms of theoretical shear buckling resistance, fundamental buckling shape, failure mechanism and ultimate buckling failure load. Through the exploratory investigations, three different restraint design concepts have been analyzed, namely consisting in:

- Linear adhesive joints along the top and bottom edges only

- Supporting metal frames with interposed linear adhesive joints and

- Mechanical point-fixing connectors

While standardized design methods available in literature and guidelines are in fact implemented and calibrated on the base of rather idealized, classical boundary conditions, a rational and safe estimation of the actual behavior and resistance of structural glass elements- as well as for construction components in general-requires dedicated and advanced studies.

In this research contribution, based on accurate and computationally efficient FE modelling procedures, as well as extended parametric studies, analytical fitting curves have been first derived from eigenvalue linear buckling analyses ( $l b a$ ) and proposed for each one of the (i) to (iii) examined boundary configurations, in order to provide a general extension of classical buckling formulations to glass shear walls differently restrained.
As shown, the major difficulty in their analysis is given by the sensitivity of the investigated shear buckling responses to a multitude of geometrical and mechanical aspects, such as the features of the glass panels themselves but also the stiffness of the adopted adhesive joints, the flexibility of the metal framing systems, the presence of possible additional point steel supports and / or gaskets/spacers, as well as the number and position of point-fixing connectors. In this sense, the proposed closed-form expression for the generalized calculation of the $k_{\tau}$ coefficients represent a key aspect for practical applications, being the Euler's critical buckling load the a fundamental parameter for buckling design purposes. The use of classical calculation methods (e.g., for ideally simply supported panels) would lead, in addition, to marked overestimation of the actual resistance, for almost of the cases of practical interest.

Successively, the applicability of a normalized design buckling curve already in use for glass shear panels ideally restrained by means of continuous simply supports along the four edges has been assessed for the aforementioned (i) to (iii) practical restraint configurations. In this latter case, the sensitivity of such restraint conditions has been further assessed by means of additional geometrically nonlinear, static incremental simulations (inls), by taking into account the effects of geometrical imperfections, local failure mechanisms in glass as well as possible damage in the examined restraint typologies. As shown, due to accurate estimation of the effect of restraints on the corresponding theoretical shear buckling responses, a rather close agreement was found for the selected restraint configurations.

Finally, a practical case study has also been discussed, to further emphasize the role of restraints on the overall shear buckling performance of a given structural glass wall. In this latter case, the provided analytical calculations highlighted a marked effect of the (i) to (iii) restraints, for a given panel geometry, compared to an idealized, simply supported case. Certainly, full-scale experimental studies should be carried out for a calibration refinement of the proposed method. It is in any case expected, towards the implementation of standardized design rules for structural glass elements, that the current exploratory research study could represent a reference theoretical background.

\section{Author's Contributions}

Chiara Bedon: Design concept, execution of simulations, data interpretation, paper writing of the paper and critical review of the scientific content of the paper.

Claudio Amadio: Design concept, data interpretation and critical review of the scientific content of the paper. 


\section{Ethics}

This article is original and contains unpublished material. The corresponding author confirms that all of the other authors have read and approved the manuscript and no ethical issues involved.

\section{References}

Amadio, C. and C. Bedon, 2013. An equivalent thickness for buckling verification of laminated glass panels under in-plane shear loads. J. Civil Eng. Sci., 2: 108-123.

Amadio, C. and C. Bedon, 2015. Effect of circumferential sealant joints and metal supporting frames on the buckling behavior of glass panels subjected to in-plane shear loads. Glass Structures Eng. DOI: 10.1007/s40940-015-0001-2

Antolinc, D., V. Rajčić and R. Žarnić, 2014. Analysis of hysteretic response of glass infilled wooden frames. J. Civil Eng. Manage., 20: 600-608. DOI: $10.3846 / 13923730.2014 .899265$

Bedon, C. and C. Amadio, 2012. Buckling of flat laminated glass panels under in-plane compression or shear. Eng. Structures, 36: 185-197. DOI: 10.1016/j.engstruct.2011.12.010

Bedon, C. and C. Amadio, 2016a. Exploratory finiteelement investigation and assessment of standardized design buckling criteria for two-side linear adhesively supported glass panels under inplane shear loads. Eng. Structures, 106: 273-287. DOI: 10.1016/j.engstruct.2015.10.033

Bedon, C. and C. Amadio, 2016b. Shear glass panels with point-fixed mechanical connections: FiniteElement numerical investigation and buckling design recommendations. Engineering Structures.

Bennison, S.J., A. Jagota and C.A. Smith, 1999. Fracture of glassy/poly (vinyl butyral) (Butacite ${ }^{\circledR}$ ) laminates in biaxial flexure. J. Am. Ceramic Society, 82: 1761-1770. DOI: 10.1111/j.1151-2916.1999.tb01997.x

Behr, R.A., 2006. Design of architectural glazing to resist earthquakes. J. Architectural Eng., 12: 122-128. DOI: 10.1061/(ASCE)1076-0431(2006)12:3(122)
CNR-DT 210/2013: Istruzioni per la progettazione, l'esecuzione ed il controllo di costruzioni con elementi strutturali di vetro. Technical Document; National Research Council, Rome, Italy.

EN 572-2, 2004: Glass in buildings-basic soda lime silicate glass products. CEN

Huveners, E.M.P., F. van Hervijnen, F. Soetens and H. Hofmeyer, 2007. Glass panes acting as shear wall. Heron, 52: 5-29.

Memari, A.M., R.A. Behr and P.A. Kremer, 2004. Dynamic racking crescendo tests on architectural glass fitted with anchored pet film. J. Architectural Eng., 10: 5-14.

DOI: 10.1061/(ASCE)1076-0431(2004)10:1(5)

Mocibob, D., 2008. Glass panels under shear loading-use of glass envelopes in building stabilization. $\mathrm{PhD}$ Thesis, EPFL Lausanne, Switzerland.

Peterson, R.E., 1953. Stress Concentration Design Factors. 1st Edn., John Wiley and Sons, New York, pp: 155.

Richter, C., B. Abeln, A. Geßler and M. Feldmann, 2014. Structural steel-glass facade panels with multi-side bonding-Nonlinear stress-strain behaviour under complex loading situations. Int. J. Adhesion Adhesives, 55: 18-28. DOI: $10.1016 /$ j.ijadhadh.2014.07.004

Simulia, 2015. ABAQUS v.9.12.3 computer software. Dassault Systemes.

Timoshenko, S.P. and J.M. Gere, 1961. Theory of Elastic Stability. 2nd Edn., McGraw-Hill, New York, pp: 541.

Van Duser, A., A. Jagota and S.J. Bennison, 1999. Analysis of glass/polyvinyl butyral laminates subjected to uniform pressure. J. Eng. Mechan., 125: 435-42.

DOI: 10.1061/(ASCE)0733-9399(1999)125:4(435)

Wellershoff, F., 2006. Nutzung der Verglasung zur Aussteifung von Gebaüdehüllen. PhD Dissertation, RTWH Aachen, Shaker Verlag. 